\title{
Ivesi koyunu yetiştiriciliğinde kızgınlık toplulaştırma ve süperovulasyon için bir model
}

\author{
A model for oestrus synchronisation and superovulation in awassi sheep breeding
}

\author{
Sabri GÜL ${ }^{1} \mathscr{D}$, Ibrahim Ethem ERDOĞAN² \\ ${ }^{1}$ Hatay Mustafa Kemal University, Faculty of Agriculture, Department of Animal Science, Antakya-Hatay, Turkey. \\ ${ }^{2}$ Adana Eastern Mediterranean Agricultural Research Institute, Adana, Turkey
}

\section{MAKALE BILGISI / ARTICLE INFO}

\section{Makale tarihçesi / Article history:}

DOI: $10.37908 /$ mkutbd.762115

Geliş tarihi /Received:01.07.2020

Kabul tarihi/Accepted:27.08.2020

\section{Keywords:}

PMSG, PGF $F_{2 \alpha}$, superovulation, oestrus synchronisation.

\footnotetext{
Corresponding author: Sabri GÜL

$\triangle:$ sabrigul@gmail.com
}

\section{ÖZET / A BSTR ACT}

\begin{abstract}
Aims: In this study, two different hormone protocols were examined for obtaining superovulation and oestrus synchronization in Awassi ewes raise in Kilis province.

Methods and Results: In the research, a total of 400 animals were used in June and July. During the period of June, the progesterone sponge was inserted into the vagina for 14 days in the treatment (P4) group, and 500 IU PMSG was injected after removal of the sponge. The control group did not receive any treatment in this term. In July, 2 doses of PGF2 $\alpha$ (PG) analogue were injected to 100 head sheep with an interval of 11 days. These animals were injected into the 500 IU PMSG subsequent the second dose of PGF2 $\alpha$ and no treatment was given to the control group in this period. The data obtained from the study were analysed with the SPSS package program. At the end of the study, fertility rate and litter sizes were calculated as $53 \%$ and $39 \%(P>0.01) ; 1.47 \%$ and $1.15 \%(P<0.01)$ in the treatment and control group respectively in June mating. According to the same group and reproductive characteristics, the order was $68 \%$ and 58 $\%(P>0.05) ; 1.29 \%$ and $1.13 \%(P<0.05)$ in July mating.

Conclusions: It was concluded that PMSG application increased the lamb yield in Awassi sheep and that hormone applications might be appropriate in August and September.

Significance and Impact of the Study: As a research outcome, the number of lambs to be obtained from each sheep will be increased to contribute to the red meat production needed by our country, and lamb deaths during out of season births will be prevented.
\end{abstract}

Atıf / Citation: Gül S, Güler IE (2021) İvesi koyunu yetiştiriciliğinde kızgınlık toplulaştırma ve süperovulasyon için bir model. MKU. Tar. Bil. Derg. 26(1) : 20-28. DOI: 10.37908/mkutbd.762115

\section{Giriş}

Ülkemizde hayvancılık, Cumhuriyetin ilan edilmesinden itibaren, diğer tarımsal faaliyetlerde olduğu gibi çok ciddi değişimler sergilemiştir. Türkiye Cumhuriyetinin kurucusu ve dönemin Cumhurbaşkanı Mustafa Kemal Atatürk, "Çiftçi ve çoban bu millet için temel unsurdur" sözüyle hayvanların ıslah edilmesi amacıyla araştırma enstitüleri kurulması talimatını vermiştir (Dernek, 2006). Hayvansal üretim, insanlara sağladığı besin kaynağııın yanı sıra tarıma dayalı sanayiye hammadde sağlaması açısından da önem arz etmektedir. Ülkemizdeki kırmızı et arzı, son yıllarda artan nüfusa paralel olarak ihtiyaç duyulan talebi karşılayamadığından, bu alanda ciddi problemler yaşanmakta, bu açığı gidermek amacıyla da zaman zaman et ithalatına başvurulmaktadır. Bu durum, et tüketiminde ülkemizi dışa bağımlı hale getirmekle beraber, hayvansal üretim alanında etkili projeksiyonlar 
geliştirilmediği takdirde, gelecek yıllarda çok ciddi ekonomik kayıpların yaşanacağını göstermektedir (Gül ve Biçer, 2020).

Kırmızı et üretimi denilince ilk akla gelen türlerden biri de koyundur. Koyun, geçmişten beri tarıma uygun olan ya da olmayan arazilerde et, süt, yapağı ve derisi ile insanoğluna hizmet etmektedir. Bu özellikleri ile bireylerin beslenmesinin yanı sıra ıslah çalışmalarında yer alarak bilime, endüstriye hammadde sağlayarak da ekonomiye destek sağlamaktadır. Hayvancılık işletmelerinde üretimde kalite ve kantititeyi artırırken sürü yönetimlerinin de iyi bir şekilde planlanması gerekmektedir. Bu noktada, bölgenin gereksinimleri, hayvanların fizyolojik özellikleri de dikkate alınarak sürü yönetim programlarının oluşturulması daha uygun olacaktır.

Geleneksel koyun yetiştiriciliğinde koyunlar yılda bir doğum yapmaktadır. Birim hayvan başına üretimi artırmanın başında özellikle sürüde genetik özelliklerin ve bakım-besleme şartlarının iyileştirilmesi gelmekle birlikte sentetik hormonlarda kullanılmaktadır. Bu hormonlar ile süperovulasyon sağlanmakta, kızgınlıklar senkronize edilerek doğumlar istenilen zamana ayarlanabilmektedir. Doğumların belirli aralıklarla gerçekleşmesi, iş gücünün daha etkin kullanılması ve yaşama gücünün yükseltilmesini sürüde bir örnek hayvanların olmasını sağlamaktadır. Böylelikle pazar ve piyasa isteklerine göre istenilen zamanda koyun eti ve sütü talebine arz sağlanmış, çayır ve meralardan daha etkin yararlanılmış, hayvanların bakımı ve beslenmesi ile bina ve diğer kaynakların kullanımı açısından kolaylıklar ve ekonomik yararlar sağlanmış olmaktadır.

İvesi koyunu, yüksek süt verimi ile tanınan ve dünyanın farklı ülkelerinde de yetiştiriciliği yapılan önemli gen kaynaklarından biridir (Yavuz ve ark., 2019). Hayvancılığın desteklenmesi ve ıslah edilmesi amacıyla, T.C. Tarım ve Orman Bakanlığı tarafından, Ülkesel Küçükbaş Hayvan Islahı Projesi kapsamında yer alan "Kilis İlinde İvesi Koyununun Islahı" isimli proje 2011 yılından beri Gaziantep ve Kilis ilinde yürütülmektedir. Islah amacıyla yürütülen bu projede yaşanan en büyük problem, yetiştiricilerin belirli bir çiftleşme takviminin olmayışı, koçları sürekli sürü içerisinde bulundurmaları ve dolayısıyla da doğumların hemen hemen yıl boyunca devam etmesidir. Bu durum ise kuzuların bir örnek olmayışına, düzenli bir sağlık koruma programının uygulanamamasına, uygun yemleme programlarının oluşturulamamasına, uzun zamana yayılan iş gücü kayıplarına dolayısıyla da ciddi kuzu ölümlerine yol açabilmektedir. Büyük ölçekli sürülere sahip yetiştiriciler, koyunların farklı zamanda doğurmasından dolayı iş gücü yetersizliğine bağlı olarak kuzu ölümlerinin meydana gelebildiğini de belirtmektedirler. Oysaki koyun yetiştiriciliğinde sürdürülebilirliğin temel yapı taşı döl verimi olup, amaç her bir anadan yılda en az bir yavru elde etmek ve döl verimini artırmaktır. Hal böyle iken yaşanan bu sorunlar devam ettikçe üretimde ve hayvan ıslahında hedefe ulaşmak oldukça zor olacaktır. Bu amaçla uygun bir çiftleşme programının hazırlanmasına intiyaç duyulmaktadır.

$\mathrm{Bu}$ çalışmada, ivesi koyunlarında kızgınlığı toplulaştırmak, kuzu verimini ve sütten kesime kadar yaşama gücünü artırmak amacıyla bir hormon uygulama modelinin geliştirilmesi hedeflenmiştir.

\section{MATERYAL ve YÖNTEM}

\section{Materyal}

Çalışma, Kilis ilinin Elbeyli ilçesine bağlı Yılanlı köyünde özel bir işletmede yürütülmüş ve yerel etik kuruldan gerekli izinler alınmıştır (Karar no: HMKU-HADYEK2017/7-3). Çalışmanın hayvan materyalini T.C. Tarım ve Orman Bakanlığı Tarımsal Araştırmalar ve Politikalar Genel Müdürlüğü (TAGEM) tarafından desteklenen "Ülkesel Halk Elinde Hayvan Islahı" projesinin alt projesi olan ve Kilis ilinde yürütülen "ivesi Koyunlarının Halk Elinde Islahı" isimli proje kapsamında yer alan özel bir işletmedeki 2-5 yaş aralığında toplam 400 baş İvesi ırkı koyun oluşturmuştur.

Çalışmada yer alan tüm hayvanlar bölgede bulunan meralarda otlatılmıştır. Meralar, mevsimsel otlar, anız kalıntıları ve çalı tipi otlardan oluşmaktadır. Koyunlar, mevsim şartlarına göre sabah erken saatlerde meraya çıkarılmış ve akşam ağıla getirilmiştir. Koyunlara mera dönüşü buğday samanı, kepek, arpa ve çiğitten oluşan karmadan hayvan başına 400-500 g olacak şekilde ek yemleme yapılmıştır. Hayvanlar, gündüzleri merada bulunan su kaynaklarından, mera dönüşü ise işletmede bulunan suluk ile sulanmıştır.

\section{Yöntem}

Deneme materyali toplam 400 baş koyun, Haziran ve Temmuz döneminde 200'er baş olmak üzere iki gruba ayrılmıştır. Haziran ayında 200 baş koyunun 100 başı deneme $\left(\mathrm{P}_{4}\right.$ grubu), diğer 100 başı ise kontrol grubu olarak rastgele ikiye ayrılmıştır. Deneme grubu koyunlara, 01/06/2017 tarihinde, tam olarak üreme sezonu içerisinde olmaması ve uygulama başarının artırılması amacıyla, $40 \mathrm{mg}$ progesteron içeren süngerler intravaginal olarak uygulanmıştır. Süngerler vagina içerisinde 14 gün kalmış ve 14. gün çıkarılmıştır. Süngerlerin çıkarılmasını müteakip $500 \mathrm{IU}$ olacak şekilde kas içi PMSG (Pregnant Mare Serum Gonadotropin) hormonu enjekte edilmiştir (Şekil 1). Uygulamadan 12 
I. $P_{4}$ süngeri çıkarıldı

$\mathrm{P}_{4}$ süngeri takıldı

\section{500 IU PMSG enjeksiyonu}

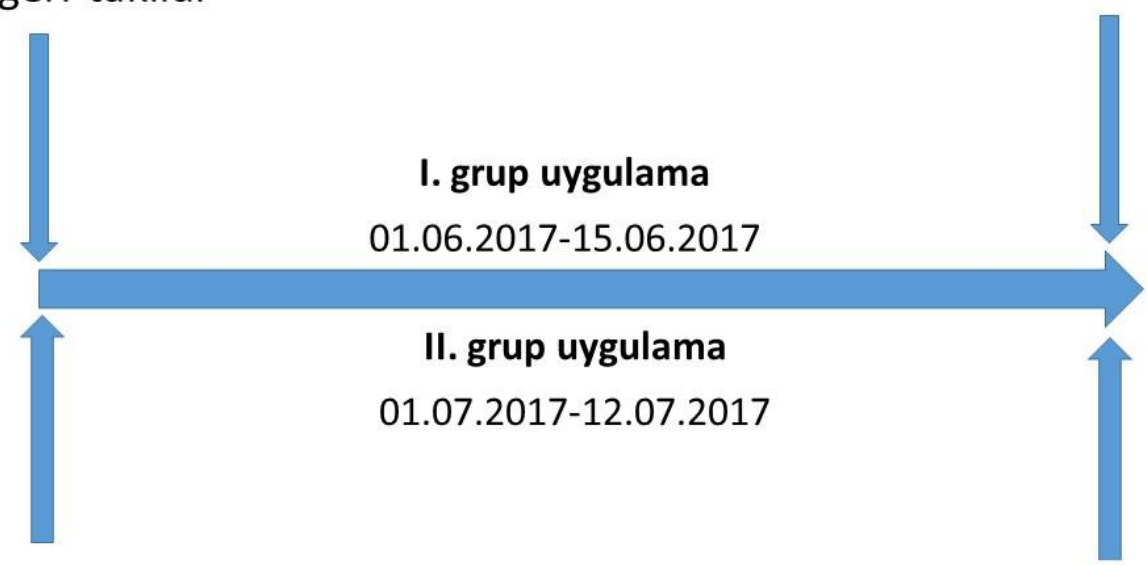

I. II. doz PGF enjeksiyonu $_{2 \alpha}$ en
II. 500 IU PMSG enjeksiyonu

I. doz PGF $2 \alpha$ enjeksiyonu

I. grup uygulama

II. grup uygulama

01.07.2017-12.07.2017
\end{abstract}

Şekil 1. Hormon uygulama protokolü

Figure 1. Protocole of hormone application saat sonra $\mathrm{P}_{4}$ ve kontrol grubuna ayrı ayrı sürülerde serbest koç katımı yapılmıştır. Temmuz dönemindeki diğer 200 baş koyundan 100 başına (PG grubu) 01/07/2017 tarihinde 1 cc PGF $2 \alpha$ analoğu kas içi enjekte edilmiştir (Şekil 1).

Bu gruptaki hayvanlara ilk uygulamayı müteakip 11. gün 1 cc olacak şekilde 2. doz $P G_{2 \alpha}$ analoğu enjekte edilmiştir. İkinci dozdan sonra hayvanlara 500 IU PMSG hormonu kas içi olarak uygulanmıştır. Bu dönemde de enjeksiyondan 12 saat sonra muamele ve kontrol grubuna ayrı ayrı sürülerde serbest koç katımı yapılmıştır. Doğum zamanında elde edilen yavruların doğum tarihleri, doğum ağırlıkları, doğum tipleri ve cinsiyetleri kaydedilmiştir. Kuzuların doğum tarihlerine göre anaların çiftleşme zamanı belirlenmiştir.

\section{istatistiksel Analiz}

Çalışmanın istatistik analizi SPSS paket programı ile değerlendirilmiştir. Gruplarda döl verim özellikleri kikare ile doğum ve 60. gün ağırlıkları ise One-way Anova ile test edilmiştir (SPSS, 2012).

\section{BULGULAR ve TARTIŞMA}

\section{Döl Verimi}

Çalışmada, Haziran ayında Progesteron $\left(\mathrm{P}_{4}\right)$ uygulamasında elde edilen döl verimlerine ait sonuçlar Çizelge 1 'de verilmiştir.

Çizelge 1 'den de görüldüğü üzere bu dönemde her iki grupta da 100'er baş koç altı koyundan $\mathrm{P}_{4}$ grubunda 53 baş koyun doğum yaparken kontrol grubunda 39 baş koyun doğum yapmıştır ( $P>0.05)$. Bu doğumlardan, $\mathrm{P}_{4}$ grubunda toplamda 78 baş kuzu doğmuş bunun \% 60.38 'i tek, \% 32.08'i ikiz, \% 7.55'i ise üçüz olarak doğmuştur. Kontrol grubunda tek doğum oranı \% 84.62, ikiz doğum oranı \% 15.38 olarak tespit edilirken üçüz doğum meydana gelmemiştir. Elde edilen bu sonuçlar neticesinde, koç altı koyuna göre kuzu verimi $\mathrm{P}_{4}$ grubunda \% 78, kontrol grubunda \% $45(\mathrm{P}<0.01)$, doğuran koyuna göre kuzu verimi, Progesteron grubunda 1.47 kontrol grubunda $1.15 \quad(\mathrm{P}<0.01)$, kuzularda yaşama gücü ise yine aynı grup sıralamasına göre \% 85.9 ve \% 86.7 ( $P>0.05)$ olarak hesaplanmıştır.. 
Çizelge 1. Progesteron (P4) grubundaki koyunlarda döl verim özellikleri

Table 1. Feritility characteristics in progesterone (P4) group

\begin{tabular}{lccc}
\hline Döl verim özellikleri & $\mathrm{P}_{4}$ & Kontrol & $\mathrm{P}$ \\
\hline Koç altı koyun sayısı (baş) & 100 & 100 & --- \\
Doğuran koyun sayısı (baş) & 53 & 39 & 0.144 \\
Koç altı koyuna göre doğum oranı (\%) & 53 & 39 & 0.144 \\
Koç Altı koyuna göre kuzu verimi (\%) & 78 & 45 & 0.003 \\
Doğan kuzu sayısı (baş) & 78 & 45 & 0.003 \\
Kuzu verimi & 1.47 & 1.15 & 0.000 \\
Sütten kesilen kuzu sayısı (baş) & 67 & 39 & 0.007 \\
Tek doğum sayısı & 32 & 33 & 0.901 \\
İkiz doğum sayısı & 17 & 6 & 0.022 \\
Üçüz doğum sayısı & 4 & --- & -- \\
Tek doğum oranı (\%) & 60.38 & 84.62 & 0.901 \\
İkiz doğum oranı (\%) & 32.08 & 15.38 & 0.022 \\
Üçüz doğum oranı (\%) & 7.55 & --- & -- \\
Yaşama gücü (\%) & 85.9 & 86.7 & 0.939 \\
\hline
\end{tabular}

Yapmış olduğumuz çalışma Özcan ve ark. (1994), Zonturlu ve ark. (2011), Özyurtlu ve ark. (2011), Özbey ve Tatlı (2001), Akbaş ve Köse. (2017) bildirişleri ile genel olarak uyum içerisinde yer almaktadır. Zonturlu ve ark., (2011)'in çalışmasında Elde etmiş olduğumuz verilerin bu araştırmacılardan farklı çıkmasının nedeni hormonun uygulama zamanı ve PMSG dozlarından kaynaklandığı söylenebilir.

Temmuz ayında kızgınlığın toplulaştırılması 11 gün ara ile uygulanan PGF2 $\alpha$ hormonu grubuna (PG) ait döl verimleri Çizelge 2 'de verilmiştir.

Çizelge 2. PG grubundaki koyunlarda döl verim özellikleri

Table 2. Feritility characteristics in PG group

\begin{tabular}{lccc}
\hline Döl verim özellikleri & $\mathrm{PGF}_{2 \alpha}$ & Kontrol & $\mathrm{P}$ \\
\hline Koç altı koyun sayısı (baş) & 100 & 100 & --- \\
Doğuran koyun sayısı (baş) & 68 & 58 & 0.373 \\
Koç altı koyuna göre doğum oranı (\%) & 68 & 58 & 0.373 \\
Koç Altı koyuna göre kuzu verimi (\%) & 88 & 66 & 0.076 \\
Doğan kuzu sayısı (baş) & 88 & 66 & 0.076 \\
Kuzu verimi & 1.29 & 1.13 & 0.000 \\
Sütten kesilen kuzu sayısı (baş) & 84 & 60 & 0.046 \\
Tek doğum sayısı & 48 & 50 & 0.840 \\
İkiz doğum sayısı & 17 & 8 & 0.072 \\
Üçüz doğum sayısı & 3 & --- \\
Tek doğum oranı (\%) & 70.59 & 86.2 & 0.840 \\
İkiz doğum oranı (\%) & 25.00 & 13.7 & 0.072 \\
Üçüz doğum oranı (\%) & 4.41 & --- & -- \\
Yaşama gücü (\%) & 95.45 & 90.9 & 0.769 \\
\hline
\end{tabular}

$\mathrm{Bu}$ dönemde de her iki grupta 100'er baş hayvan kullanılmış ve PG grubunda 68 baş hayvan, kontrol grubunda ise 58 baş hayvan doğum yapmıştır ( $P>0.05)$. Bu doğumlardan PG grubunda toplam 88 baş, kontrol grubunda ise 66 baş kuzu doğmuştur $(P>0.05)$. PG grubunda kuzuların \% 70.59'u tek, \% 25.00'i ikiz, \% 4.41'i üçüz olarak doğmuştur. Kontrol grubunda tek doğanların oranı \% 86.2, ikiz doğanların oranı \% 13.7 iken üçüz doğum meydana gelmemiştir. Gruplar arasında tek ve çoğuz doğumlar arasında sayısal farklılık olmasına rağmen istatistiksel olarak önemsiz bulunmuştur $(P>0.05)$. Bu sonuçlara göre koç altı koyuna göre kuzu verimi PG grubunda \% 68, kontrol grubunda \% 58 $(P>0.05)$, doğuran koyuna göre kuzu verimi PG grubunda 
\% 1.29, kontrol grubunda \% $1.13(\mathrm{P}<0.05)$, kuzularda yaşama gücü $P G$ grubunda $\% 95.45$, kontrol grubunda ise \% 90.9 ( $P>0.05$ ) olarak hesaplanmıştır.

$\mathrm{PGF}_{2 \alpha}$ ile beraber PMSG uygulamasının koyunlarda kuzu verimini artırdığı farklı çalışmalarda da ifade edilmiştir.

Öztürkler ve ark. (2003), Sözbilir ve ark. (2006), Ocak (2007), Yadi ve ark. (2011), Elmarimi ve ark. (2015), 11 gün ara ile iki doz $\mathrm{PGF}_{2 \alpha}$ kullanarak çalışma yürütmüşlerdir. Araştırmacılar, $P \mathrm{FF}_{2 \alpha}$ ve PMSG hormonunun kızgınlıkların normal dönemde senkronize edilebildiğini ve döl verimini artırmış olduğunu bildirmişlerdir. Özellikle Öztürkler ve ark. (2003) ve Ocak (2007)'in çalışmalarında görüldüğü üzere PGF $_{2 \alpha}$ ve PMSG hormonlarının birlikte kullanımı döl verimini olumlu yönde etkilemektedir. Sunulan PG grubu çalışmasında ve diğer araştırmacıların çalışmaların da uygulama dönemi, uygulanan PMSG hormonunun dozajları, PGF $2 \alpha$ 'nın çift

Çizelge 3. $\mathrm{P}_{4}$ grubunda doğum ve 60 . gün ağırlıkları $(\mathrm{kg})$

Table 3 Birth and weaning weights in $\mathrm{P}_{4}$ group $(\mathrm{kg})$

\begin{tabular}{lllll}
\hline Doğum ağırlığı & & & & \\
\hline Gruplar & $\mathrm{n}$ & Erkek & $\mathrm{n}$ & Dişi \\
\hline Kontrol & 23 & $3.5 \pm 0.11$ & 2 & $3.3 \pm 0.10$ \\
Muamele & 36 & $3.6 \pm 0.15$ & 2 & $3.2 \pm 0.77$ \\
\hline $\mathbf{P}$ & & 0.733 & & 0.451 \\
\hline 60 . gün ağırlığı & & & 22 & \\
\hline Kontrol & 17 & $16.6 \pm 0.76$ & 38 & $16.2 \pm 0.33$ \\
Muamele & 29 & $15.8 \pm 0.48$ & & 0.219 \\
\hline $\mathbf{P}$ & & 0.370 & & \\
\hline
\end{tabular}

Çalışma kapsamında Haziran ayı grubunda doğan erkek kuzularda doğum ağırlığı bakımından kontrol ve muamele grupları arasında istatistiksel bir farklılık görülmemiştir $(P>0.05)$. Dişi kuzularda da benzer durum sergilenmiş olup $(P>0.05)$ genel ortalama olarak yine gruplar arasında anlamlı bir farklılık tespit edilmemiştir $(P>0.05)$. Bu dönemde 60. gün ağırlıkları dikkate alındığında yine hem cinsiyet bakımından hem de genel olarak gruplar arasında istatistiksel bir farklılık belirlenmemiştir ( $P>0.05)$.

Gruplarda cinsiyet ve doğum tipine göre doğum ve 60 . gün ağırlıkları Çizelge 4 'te verilmiştir. Cinsiyetin ve doz veya tek doz kullanılması, PGF $2 \alpha$ 'nın çift doz uygulama aralığı, PMSG uygulama yapılan dönem, yapılan aşım şekline ve uygulamada kullanılan koyun ırkına göre farklııklar olabildiği gözlenmekle birlikte elde etmiş olduğumuz değerler, diğer araştırmacıların çalışmalarındaki döl verim parametre değerleri ile uyum içerisindedir.

\section{Doğum ve Sütten Kesim Ağırlıkları}

Hayvansal üretimde döl verimini artırmak ve sürdürülebilirlik açısından doğan yavruların yaşamasını sağlamak yetiştiriciliğin temel esasları arasında yer almaktadır. Haziran ayında hormon uygulaması yapılan ve Kasım ayında doğum yapan koyunlardan doğan kuzulara ait doğum ve 60 . gün ağırlıkları Çizelge 3'te verilmiştir. doğum tipinin, doğum ağırlığına etkisi bilinen ve beklenen bir sonuç olup birçok çalışmada bildirilmiştir (Yaralı ve Karaca, 2004; Ülker ve ark., 2004; Gül ve Keskin, 2010; Biçer ve ark., 2019). Buna göre Çizelge 4 'ten de görüleceği üzere $\mathrm{P}_{4}$ ve Kontrol gruplarında grup sıralamalarına göre doğum ağırlıkları tek doğan erkek kuzularda $4.1 \pm 0.10 \mathrm{~kg}$ ve $3.9 \pm 0.09 \mathrm{~kg}(P>0.05)$, ikizlerde $2.6 \pm 0.21 \mathrm{~kg}$ ve $3.3 \pm 0.13 \mathrm{~kg}(P<0.05)$ olarak tespit edilirken, üçüz doğum sadece $\mathrm{P}_{4}$ grubunda görülmüştür (2.5 \pm 0.39$)$. Bu durum PMSG uygulamasının bu dönemde etkili olduğunun da bir göstergesi şeklinde yorumlanabilir. 
Çizelge 4. $\mathrm{P}_{4}$ grubunda cinsiyet ve doğum tipine göre doğum ve 60. gün ağırlıkları (kg)

Table 4 . Birth and weaning weight in $\mathrm{P}_{4}$ group by sex and birth type $(\mathrm{kg})$

\begin{tabular}{|c|c|c|c|c|c|c|c|}
\hline \multicolumn{8}{|c|}{ Doğum ağırlığı (Erkek) } \\
\hline Gruplar & $n$ & Tek & $n$ & ikiz & $P$ & $\mathrm{n}$ & Üçüz \\
\hline Kontrol & 17 & $3.9 \pm 0.09$ & 6 & $2.6 \pm 0.21$ & 0.000 & --- & --- \\
\hline Muamele & 14 & $4.1 \pm 0.10$ & 15 & $3.3 \pm 0.13$ & 0.000 & 7 & $2.7 \pm 0.27$ \\
\hline $\mathbf{P}$ & & 0.157 & & 0.010 & & & \\
\hline \multicolumn{8}{|c|}{ 60. gün ağırlığı (Erkek) } \\
\hline Kontrol & 12 & $17.3 \pm 1.01$ & 5 & $14.8 \pm 0.28$ & 0.154 & --- & --- \\
\hline Muamele & 13 & $16.7 \pm 0.65$ & 10 & $14.9 \pm 0.95$ & 0.196 & 6 & $15.1 \pm 1.06$ \\
\hline $\mathbf{P}$ & & 0.668 & & 0.951 & & & --- \\
\hline \multicolumn{8}{|c|}{ Doğum ağırlığı (Dişi) } \\
\hline & $\mathrm{n}$ & Tek & $\mathrm{n}$ & İkiz & $P$ & $\mathrm{n}$ & Üçüz \\
\hline Kontrol & 16 & $3.4 \pm 0.08$ & 6 & $2.9 \pm 0.23$ & 0.018 & --- & --- \\
\hline Muamele & 18 & $3.5 \pm 0.09$ & 19 & $3.1 \pm 0.10$ & 0.000 & 5 & $2.5 \pm 0.39$ \\
\hline $\mathbf{P}$ & & 0.616 & & 0.532 & & & --- \\
\hline \multicolumn{8}{|c|}{ 60. gün ağırlığı (Dişi) } \\
\hline Kontrol & 16 & $16.3 \pm 0.44$ & 6 & $16.1 \pm 0.30$ & 0.869 & --- & --- \\
\hline Muamele & 18 & $16.9 \pm 0.34$ & 18 & $14.5 \pm 0.53$ & 0.000 & 2 & $11.8 \pm 1.06$ \\
\hline $\mathbf{P}$ & & 0.212 & & 0.097 & & & --- \\
\hline
\end{tabular}

Progesteron grubunda tek doğan erkek kuzularda doğum ağırlığı bakımından muamele ve kontrol grupları arasında sayısal bir farklılık gözlemlenmiş fakat bu farklılık istatistiksel olarak anlamsız bulunmuş ( $P>0.05)$, sütten kesim ağırlıkları hemen hemen eşit çıkmıştır ( $P>0.05)$. Tek doğan dişi kuzularda doğum ağırlıkları kontrol ve muamele grubunda yine birbirlerine çok yakın (3.4 \pm 0.08 kg ve $3.5 \pm 0.09 \mathrm{~kg}$ ) olarak belirlenmiştir ( $P>0.05)$. Aynı durum ikiz doğan dişi kuzularda da sergilenmiş olup ( $P>0.05)$ sadece uygulama grubunda üçüz doğum gerçekleşmiştir. Sütten kesim ağırlıkları bakımından da
(60. gün) hem dişiler hem erkekler aynı performansı sergilemişlerdir $(\mathrm{P}>0.05)$. Tek doğan kuzularda, uygulama grubu kontrol grubuna göre çok az bir üstünlük sağlamış, ikizlerde ise kontrol grubu muamele grubuna göre yüksek çıkmasına rağmen istatistiksel olarak sonuç önemsiz bulunmuştur ( $P>0.05)$. Elde etmiş olduğumuz bulgular ile Gül ve Keskin, 2010, Keskin ve ark. 2005, Oflaz (2018), Yaralı ve Karaca, (2004)'ün bildirişleri ile benzer durumdadır.

Temmuz dönemi PG uygulamasında doğan kuzuların doğum ve 60. gün ağırlıkları Çizelge 5'te verilmiştir.

Çizelge 5. PG grubunda doğum ve 60. gün ağırlıkları (kg)

Table 5. Birth and weaning weight in PG group (kg)

\begin{tabular}{|c|c|c|c|c|c|c|}
\hline \multicolumn{7}{|c|}{ Doğum ağırlığı } \\
\hline Gruplar & $n$ & Erkek & $\mathrm{n}$ & Dişi & $\mathrm{P}$ & Genel \\
\hline Kontrol & 32 & $3.6 \pm 0.10$ & 34 & $3.2 \pm 0.07$ & 0.004 & $3.4 \pm 0.07$ \\
\hline Muamele & 37 & $3.6 \pm 0.11$ & 51 & $3.1 \pm 0.06$ & 0.023 & $3.4 \pm 0.06$ \\
\hline$P$ & & 0.688 & & 0.872 & & 0.675 \\
\hline \multicolumn{7}{|c|}{ 60. gün ağırlığı } \\
\hline Kontrol & 32 & $16.9 \pm 0.48$ & 33 & $16.2 \pm 0.50$ & 0.338 & $16.5 \pm 0.35$ \\
\hline Muamele & 37 & $16.6 \pm 0.44$ & 49 & $16.1 \pm 0.40$ & 0.031 & $16.3 \pm 0.30$ \\
\hline $\mathrm{P}$ & & 0.749 & & 0.862 & & 0.703 \\
\hline
\end{tabular}

Temmuz ayında çiftleşen koyunlardan Aralık ayında doğan erkek kuzularda kontrol ve uygulama gruplarında aynı doğum ağırlıkları tespit edilmiştir ( $P>0.05)$. Doğum ağırlığı bakımından dişi kuzularda da benzer durum görülmüştür $(P>0.05)$. Erkek ve dişi kuzularda sütten kesim ağırlığı (60. gün) değerleri de kontrol ve muamele 
gruplarında birbirlerine çok yakın değerler elde edilmiş ve aralarındaki küçük farklılıklar istatistiksel olarak önemsiz bulunmuştur ( $P>0.05)$.
Temmuz ayında çiftleştirilen ve Aralık ayında doğan kuzularda doğum tipi ve cinsiyete göre doğum ve 60. gün ağırlıkları Çizelge 6 'da verilmiştir.

Çizelge 6. PG grubunda cinsiyet ve doğum tipine göre doğum ve 60. gün ağıllıkları (kg)

Table 6 . Birth and weaning weight in PG group by sex and birth type $(\mathrm{kg})$

\begin{tabular}{|c|c|c|c|c|c|c|c|}
\hline \multicolumn{8}{|c|}{ Doğum ağırlığı (Erkek) } \\
\hline Gruplar & $\mathrm{n}$ & Tek & $\mathrm{n}$ & ikiz & $P$ & $\mathrm{n}$ & Üçüz \\
\hline Kontrol & 22 & $3.9 \pm 0.11$ & 10 & $3.0 \pm 0.16$ & 0.000 & --- & --- \\
\hline Muamele & 21 & $4.0 \pm 0.09$ & 14 & $3.0 \pm 0.10$ & 0.000 & 2 & $2.4 \pm 0.10$ \\
\hline$P$ & & 0.505 & & 0.924 & & & --- \\
\hline \multicolumn{8}{|c|}{ 60. gün ağırlığı (Erkek) } \\
\hline Kontrol & 19 & $17.5 \pm 0.55$ & 8 & $16.0 \pm 0.60$ & 0.028 & --- & --- \\
\hline Muamele & 11 & $17.3 \pm 0.53$ & 13 & $15.3 \pm 0.74$ & 0.013 & 1 & 10.3 \\
\hline$P$ & & 0.813 & & 0.455 & & & --- \\
\hline \multicolumn{8}{|c|}{ Doğum ağırlığı (Dişi) } \\
\hline & $\mathrm{n}$ & Tek & $\mathrm{n}$ & İkiz & $P$ & $\mathrm{n}$ & Üçüz \\
\hline Kontrol & 28 & $3.4 \pm 0.10$ & 6 & $2.7 \pm 0.15$ & 0.000 & --- & --- \\
\hline Muamele & 27 & $3.6 \pm 0.08$ & 20 & $2.9 \pm 0.10$ & 0.000 & 4 & $2.3 \pm 0.35$ \\
\hline $\mathrm{P}$ & & 0.114 & & 0.380 & & & --- \\
\hline \multicolumn{8}{|c|}{ 60. gün ağırlığı (Dişi) } \\
\hline Kontrol & 27 & $16.4 \pm 0.61$ & 6 & $15.1 \pm 0.42$ & 0.028 & --- & --- \\
\hline Muamele & 27 & $16.8 \pm 0.60$ & 19 & $15.2 \pm 0.47$ & 0.128 & 3 & $12.1 \pm 0.95$ \\
\hline $\mathrm{P}$ & & 0.658 & & 0.901 & & & --- \\
\hline
\end{tabular}

Prostaglandin $F_{2 \alpha}$ grubunda kontrol ve muamele gruplarında tek doğumlarda doğum ağırlık değerleri Haziran ayı grubunda olduğu gibi birbirlerine yakın, ikiz doğumlarda ise aynı doğum ağırlıkları $(3.0 \pm 0.16 \mathrm{~kg}$ ve $3.0 \pm 0.10 \mathrm{~kg}$ ) elde edilmiştir $(P>0.05)$. $P G_{2 \alpha}$ grubunda $\mathrm{da}, \mathrm{P}_{4}$ grubunun kontrol grubu koyunlarında olduğu gibi üçüz doğum gözlemlenmemiştir. Tek doğan erkek kuzularda 60. gün ağırlıkları birbirlerine yakın bulunmuş, ikiz doğanlar arasında ise doğum ağırlıkları eşit çıkmasına rağmen bu dönemde sayısal bir farklılık oluşmuştur. Tamamen çevresel etmenlere bağlı olduğu düşünülen bu farklılıklar istatistiksel olarak önemsiz tespit edilmiştir $(P>0.05)$. Tek ve ikiz doğan dişi kuzularda doğum ağırlıkları açısından anlamlı bir farklııı belirlenmemiştir $(P>0.05)$. Dişi doğan üçüz kuzu kontrol grubunda meydana gelmemiş olup muamele grubunda bu değer $2.3 \pm 0.35 \mathrm{~kg}$ olarak tartılmıştır. Sütten kesime kadar ki gelişim döneminde tek ve ikiz kuzular yine benzer performans sergilemiştir. Her iki doğum tipinde de gruplar arasındaki, sayısal farklııkların istatistiksel olarak önemsiz oldukları belirlenmiştir ( $P>0.05)$. Erkek ve dişi kuzularda 60. gün ağırlıkları dikkate alındığında yine kontrol ve muamele grupları arasında istatistiksel olarak bir farklılık tespit edilmemiştir ( $P>0.05)$.

Kul ve Akcan (2002), İvesi koyunlarında yapmış oldukları çalışmada ortalama doğum ağırlıklarını erkeklerde 4.15 $\mathrm{kg}$, dişilerde $3.99 \mathrm{~kg}$, tek doğanlarda $4.30 \mathrm{~kg}$, ikiz doğanlarda $3.73 \mathrm{~kg}$ olarak bildirilmiştir. Kuzularda 60 . gün ortalama sütten kesim ağırıklarını $11.53 \mathrm{~kg}$, dişilerde $11.33 \mathrm{~kg}$, erkeklerde $11.81 \mathrm{~kg}$, tekiz doğanlarda $11.96 \mathrm{~kg}$, ikiz doğanlarda 10.34 kg; Yakan ve ark. (2012), Ankara şartlarında yaptıkları çalışmada İvesi koyunlarında doğum ağırlığını ortalama $4.4 \pm 0.17,60$. gün sütten kesim ağırığını $19.62 \pm 0.58$ olarak bildirmişlerdir. Elde etmiş olduğumuz bulgular, 60 . gün ağırlıkları bakımından Yakan ve ark. (2012)'ın bildirişleri ile yakın, Kul ve Akcan (2002)'nın çalışmalarından yüksek olarak bulunmuştur. Uygulamalar arasındaki doğum ve sütten kesim ağırlıklarındaki farklılı̆ın bakım-besleme, bölge ve doğum zamanı ve verim yönünden ciddi farklılıkların olmasından kaynaklandığı söylenebilir.

Araştırmada doğum ayının kuzularda gelişim özelliklerine etkisine ait değerler Çizelge 7'de verilmiştir. 
Çizelge 7. Kuzularda doğum zamanının doğum ve 60. gün ağırlıkları üzerine etkisi (kg)

Table 7. Effect of season on birth and weaning weight in lambs $(\mathrm{kg})$

\begin{tabular}{|c|c|c|c|c|c|}
\hline \multicolumn{6}{|c|}{ Doğum ağırlığı } \\
\hline Gruplar & $\mathrm{n}$ & Kontrol & $\mathrm{n}$ & Muamele & Genel \\
\hline $\mathrm{P}_{4}$ & 45 & $3.4 \pm 0.09$ & 78 & $3.3 \pm 0.07$ & $3.4 \pm 0.56$ \\
\hline PG & 66 & $3.4 \pm 0.06$ & 88 & $3.4 \pm 0.07$ & $3.4 \pm 0.50$ \\
\hline$P$ & & 0.935 & & 0.601 & 0.154 \\
\hline \multicolumn{6}{|c|}{ 60. gün ağırlığı } \\
\hline $\mathrm{P}_{4}$ & 39 & $16.4 \pm 0.38$ & 67 & $16.2 \pm 0.50$ & $15.9 \pm 0.23$ \\
\hline PG & 60 & $16.5 \pm 0.36$ & 84 & $16.1 \pm 0.40$ & $16.4 \pm 0.22$ \\
\hline$P$ & & 0.835 & & 0.118 & 0.156 \\
\hline
\end{tabular}

Çalışmamızda doğumlar birbirlerine takip eden iki ayda meydana gelmiştir. Çizelge7'den de görüldüğü üzere tüm gruplarda gerek doğum gerekse 60. gün ağırlıkları bakımından istatistiksel bir farklılık görülmemiştir $(P>0.05)$. Bu sonuç ise üreticilerin doğumu planlarken her iki dönemi de seçebilmelerine avantaj sağlamış olacaktır.

Sonuç olarak, ülkemizin kırmızı et ihtiyacının karşılanmasında koyun sayısını arttırmanın öneminin vurgulandığı günümüzde, yerli gen kaynaklarımız içerisindeki koyunlarda birim hayvandan daha fazla yavru alabilmek ve kuzu ölümlerini azaltabilmek için sürdürülebilir ve pratik üretim modellerinin ortaya konulması elzemdir. Bu amaçla yapılan bu çalışmada, iki farklı dönemde uygulanan iki modelle de iyi sonuçlar alınmıştır. Bu kapsamda özellikle PMSG'nin etkisi ile azımsanmayacak düzeyde kuzu üretiminde artışların olduğu belirlenmiştir. $\mathrm{PGF}_{2 \alpha}$ 'nın 11 gün ara çift doz uygulamasının ardından PMSG uygulaması ilavesinin daha kolay ve pratik uygulanabilirliği de ayrı bir avantaj sağlamaktadır. Ayrıca, yapılan çalışma ile ìvesi koyunlarında üreme sezonunun Haziran ayında tam aktif olmadığı, Temmuz ayında ise kısmen aktif olduğu kanısına varılmıştır. Bunun yanı sıra bu iki hormon uygulama metodunun, Ağustos-Eylül aylarında da uygulanarak verimlerin tespit edilmesinin yararlı olacağı düşünülmektedir.

\section{ÖZET}

Amaç: Bu çalışmada, Kilis ilinde yetiştirilen İvesi koyunlarında kızgınlığın toplulaştırılması ve süperovulasyon elde etmek amacıyla iki farklı hormon uygulaması yapılmıştır.

Yöntemler ve Bulgular: Araştırmada, Haziran ve Temmuz aylarında 200 'er baş olmak üzere toplam 400 baş hayvan kullanılmıştır. Haziran döneminde deneme $\left(P_{4}\right)$ grubundaki 100 baş hayvana 14 gün süre ile progesteron içeren sünger, vaginal yolla uygulanmış ve süngerin çıkarılmasına müteakip $500 \mathrm{IU}$ gebe kısrak serumu hormonu (PMSG) enjekte edilmiştir. Kontrol grubuna ise herhangi bir muamele yapılmamıştır. Temmuz ayında ise 100 baş koyuna 11 gün ara ile $2 \mathrm{doz}$ prostaglandin $F_{2 \alpha}$ (PG grubu) analoğu enjekte edilmiştir. $\mathrm{Bu}$ hayvanlara 2 . dozu müteakip 500 IU PMSG enjeksiyonu yapılmış ve bu dönemde kontrol grubuna herhangi bir muamele yapılmamıştır. Çalışmadan elde edilen veriler SPSS paket programı ile analiz edilmiştir. Çalışma sonunda, Haziran ayında deneme ve kontrol grubunda koç altı koyuna göre doğum oranını $\% 53$ ve \% 39 ( $P>0.01)$, doğuran koyuna göre kuzu verimini \% 1.47 ve $\% 1.15(P<0.01)$; Temmuz ayında yine aynı grup ve özellik sıralamasına göre \% 68 ve \% 58 ( $P>0.05)$; 1.29 ve $1.13(P<0.05)$ olarak hesaplanmıştır.

Genel Yorum: Sonuç olarak PMSG uygulamasının koyunlarda kuzu verimini artırdığı ve bu uygulamaların Ağustos ve Eylül aylarında da yapılarak çalışmanın genişletilmesinin yararlı olabileceği kanaatine varılmıştır. Çalışmanın Önemi ve Etkisi: Araştırma neticesinde ülkemizin ihtiyaç duyduğu kırmızı et üretimine katkı sağlamak amacıyla her bir koyundan elde edilen kuzu sayısı artmış, aynı zamanda mevsim dışı doğumlarda meydana gelen kuzu ölümlerinin önüne geçilmiş olacaktır.

Anahtar Kelimeler: PMSG, PGF $2 \alpha$, Süperovulasyon, kızgınlık toplulaştırma

\section{TEŞEKKÜR}

Bu çalışma Hatay Mustafa Kemal Üniversitesi Bilimsel Araştırma Projeleri Komisyonu Başkanlığı tarafından maddi olarak desteklenmiştir (Proje No: 16902).

\section{ÇIKAR ÇATIŞMA BEYANI}

Makale yazarları aralarında herhangi bir çıkar çatışması olmadığını beyan ederler. 


\section{ARAŞTIRMACILARIN KATKI ORANI BEYANI}

Yazarlar çalışmaya eşit oranda katkı sağlamış olduklarını beyan eder.

\section{KAYNAKLAR}

Akbaş ÖF, Köse AM (2017) Aşım sezonunda FGA ile senkronize edilen ivesi koyunlarında PGF2 $\alpha$ ve PMSG uygulamasının bazı reprodüktif parametreler üzerine etksi. Eurasan Journal of Vet Sci. 33(2): 107-112.

Biçer O, Keskin M, Gül S, Gündüz Z, Oflaz NZ, Behrem S (2019) Comparison of yield characteristics of brown and black headed Awassi sheep. Mustafa Kemal University Journal of Agricultural Sciences 24(1): 5861.

Dernek Z (2006) Cumhuriyet'in kuruluşundan Günümüze tarımsal gelişmeler. Süleyman Demirel Üniversitesi Ziraat Fakültesi Dergisi 1(1): 1-12.

Elmarimi A, Mariol N, Ahmed J, Sassi MF, Gaja A (2015) Fertility of Libyan Barbary sheep treated with prostaglandin $F 2 \alpha$ (PGF2 $\alpha$ ) in different seasons. World Journal of Agricultural Research 3(5): 174-178. doi: 10.12691/wjar-3-5-4.

Gül S, Keskin M (2010) Reproductive characteristics of Awassi ewes under Cornell alternate month accelerated lambing system. Italian Journal of Animal Science 9(49): 255-259.

Gül S, Biçer O (2020). Fattening performance of Awassi sheep and evaluation of carcasses according to EAAP method. Mustafa Kemal University Journal of Agricultural Sciences 25(1): 20-26.

Keskin M, Biçer O, Gül S, Sarı A (2005) İvesi koyunlarında iki yılda üç kuzulatma ile döl veriminin artırılması üzerine bir araştırma. Lalahan Hay. Arast. Enst. Derg. 45(1): 33-39.

Kul S, Akcan A (2002) İvesi ve Ost-Friz x İvesi melez (F1) kuzularda büyüme, yaşama gücü ve bazı vücut ölçüleri. Uludağ Univ. J. Fac. Vet. Med. 21: 109-114.

Ocak A (2007) Sakız ırkı melezi koyunlarda kısa süreli uygulamalar ile mevsim içi östrus senkronizasyonu. Selçuk Üniversitesi Sağlık Bilimleri Enstitüsü Dölerme Ve Suni Tohumlama Anabilim Dalı Doktora Tezi, Konya.

Oflaz NZ (2018) Gaziantep ve Kilis illerinde yetiştirilen İvesi koyunlarının bazı morfolojik ve fizyolojik özellikleri bakımından karşılaştırılması. Mustafa Kemal Üniversitesi Fen bilimleri Enstitüsü Zootekni Anabilim Dalı Yüksek Lisans Tezi, Hatay.

Özbey O, Tatlı P (2001) İvesi koyunlarında flushing ve sinkronizasyon uygulamalarının döl verimi üzerine etkisi. Journal of Fac. Vet. Med. 20: 109-115.
Özcan L, Torun O, Bakır B (1994) Ceylanpınar Tarım İşletmesinde yetiştirilen ivesilerde chrono-gest yöntemine göre daha fazla döl alma olanakları. Ç.Ü.Z.F Dergisi 9(4): 101-114.

Öztürkler Y, Colak A, Baykal A, Guven B (2003) Combined effect of a prostaglandin analogue and progestagen treatment for 5 days on oestrus synchronisation in Tushin ewes. Indian Vet. J. 80: 917-920.

Özyurtlu N, Ay SS, Küçükaslan I, Güngör Ö, Aslan S (2011) Effect of subsequent two short-term, short-term, and long-term progestagen treatments on fertility of awassi ewes out of the breeding season. Ankara Üniv Vet Fak Derg. 58: 105-109.

Sözbilir NB, Maraşlı Ş, Öztürkler Y, Uçar Ö (2006) Effects of double injectons of PGF2a at different intervals on some reproductive traits in Tuj ewes. Turk. J. Vet. Anim. Sci. 30: 207-211.

Ülker H, Gökdal Ö, Aygün T, Karakuş F (2004) Karakaş ve Norduz koyunlarının temel üreme özellikleri bakımından karşılaştırılması. Yüzüncü Yıl Üniversitesi, Ziraat Fakültesi, Tarım Bilimleri Dergisi 14(1): 59-63.

Yadi J, Moghaddam M F, Khalajzadeh S, Solati AA (2011) Comparison of estrus synchronization by PGF2 $\alpha$, CIDR and sponge with PMSG in Kalkuhi ewes on early anestrous season. International Conference on Asia Agriculture and AnimalIPCBEE IACSIT Press, Singapoore, 13: 61-65.

Yakan A, Ünal N, Dalcı MT (2012) Ankara şartlarında Akkaraman, İvesi ve Kıvırcık ırklarında döl verimi, büyüme ve yasama gücü. Lalahan Hay. Arast. Enst. Derg. 52(1): 1-10.

Yaralı E, Karaca O (2004) Kıvırcık koyunları farklı senkronizasyon uygulamalarında kuzu üretimi ile kuzuların canlı ağırlık ve bel gözü ultrasonik ölçüm parametreleri. 4. Ulusal Zootekni Bilim Kongresi, 1: 136-142.

Zonturlu AK, Özyurtlu N, Kaçar C (2011) Effect of different doses PMSG on estrus synchronization and fertility in Awassi ewes synchronized with progesterone during the transition period. Kafkas Univ. Vet. Fak. Derg. 17(1): 125-129.

Yavuz C, Keskin M, Gül S (2019) Doğu Akdeniz bölgesi koşullarında farklı koyun ırklarının bazı adaptasyon özelliklerinin karşılaştırılması. Mustafa Kemal University Journal of Agricultural Sciences 24(2): 140145. 